\title{
El consumo de leche fortificada puede reducir la incidencia de diarrea y neumonía en la infancia
}

\author{
Fortified milk may reduce the incidence of diarrhea and pneumonia in young children
}

Sazawal S. BMJ. 2007 Jan 20;334(7585):140.

\begin{abstract}
Objetivo
Evaluar sobre la morbilidad en los niños, la eficacia y la aceptabili-
\end{abstract} dad de la leche fortificada (LF) con micronutrientes específicos.

\section{Diseño \\ Estudio controlado, aleatorizado y doble ciego.}

\section{Lugar}

Sangam Vihar, población periurbana de Nueva Delhi, India.

\section{Pacientes}

Niños de uno a tres años de edad de familias con residencia permanente.

\section{Intervención}

Se realizó una aleatorización estratificada*. El grupo control (317 niños) recibió leche no fortificada y el grupo intervención (316) recibió durante un año tres tomas diarias de LF con zinc $(7,8 \mathrm{mg})$ hierro $(9,6 \mathrm{mg})$, cobre $(0,27 \mathrm{mg})$ selenio $(4,2 \mu \mathrm{g})$ vitamina $A(156 \mu \mathrm{g})$ C $(40,2 \mathrm{mg})$ y $\mathrm{E}(7,5 \mathrm{mg})$.

\section{Medición de resultados principales}

Días de enfermedad severa, incidencia y prevalencia de diarrea, e incidencia de infecciones respiratorias agudas bajas

\section{Resultados principales}

La adherencia a la toma de la leche fue similar en ambos grupos. El número de episodios de diarrea por niño por año fue 4,46 en el grupo LF y 5,36 en el grupo control; los de infecciones respiratoria agudas bajas fueron 0,62 y 0,83 respectivamente. El consumo de LF se asoció a una reducción del $15 \%$ en los días con enfermedad severa (IC95\% 5 a 24) a una reducción del 18\% (7 a 27) en la incidencia de diarrea y a un 26\% (3 a 43) en la de infecciones respiratorias agudas bajas. El mayor efecto beneficioso ocurrió en los menores de dos años.

Ver tabla 1: efectos del uso de leche fortificada sobre la morbilidad de niños de uno a tres años.

\begin{tabular}{|c|c|c|c|}
\hline $\begin{array}{l}\text { Número absoluto en todos los niños } \\
\text { de uno a tres años según el tipo de } \\
\text { leche utilizada }\end{array}$ & \begin{tabular}{|c} 
Fortificada \\
$(n=316)$
\end{tabular} & $\begin{array}{c}\text { No } \\
\text { fortificada } \\
(n=317)\end{array}$ & RR (IC95\%) \\
\hline De episodios de diarrea & 1408 & 1700 & $0,82(0,73$ a 0,93$)$ \\
\hline De infecciones respiratorias agudas bajas & 195 & 262 & $0,74(0,57$ a 0,97$)$ \\
\hline De das con enfermedad severa & 530 & 621 & $0,85(0,76$ a 0,95$)$ \\
\hline
\end{tabular}

\section{Conclusiones}

La LF es bien aceptada y su consumo puede reducir significativamente las morbilidades más comunes en los niños de uno a tres años.

Fuente de financiamiento/conflicto de interés de los autores: no referida.

\section{Comentario}

Este estudio ayuda a valorar los efectos sobre la inmunidad atribuibles a la fortificación de la dieta con micronutrientes, permitiendo además diferenciar que estos no serían consecutivos a un mayor aporte calórico ya que ambos grupos recibieron leches de similar composición de proteínas, hidratos de carbono y grasas.

El déficit de zinc es más común en donde el consumo de carne es bajo y la incidencia de diarreas alta, ya que éstas provocan grandes pérdidas de este elemento. Su diagnóstico es difícil, siendo necesaria una prueba terapéutica evaluando la respuesta en el crecimiento y en parámetros inmunológicos (en especial, inmunidad celular) ${ }^{1}$.

Entre los micronutrientes evaluados globalmente en esta investigación, la vitamina $\mathrm{A}$ y el zinc se asocian clásicamente a la mejoría de la inmunidad, existiendo ya la recomendación de la Organización Mundial de la Salud (OMS) ${ }^{2}$ de utilizar megadosis de vitamina $A$ en las áreas con una mortalidad anual en niños menores de cinco años mayor a 50/1000.

En Argentina, es muy prevalente el déficit de hierro $-34 \%$ de los niños de seis a 24 meses de edad ${ }^{3}$ - y no se constataron déficits de vitamina A que justifiquen las medidas recomendadas por la OMS. En Argentina se aprobaron dos leyes sobre fortificación de alimentos': la 25459-01 establece la fortificación de las leches en polvo que se distribuyen en los programas materno infantiles de todo el país con hierro, zinc y vitamina $\mathrm{C}$; y la 25630-02 la suplementación de todas las harinas de trigo disponibles en el mercado con hierro, acido fólico y otras vitaminas del complejo $\mathrm{B}$.

\section{Conclusión de los comentadores}

Si bien esta intervención se asoció a una reducción estadísticamente significativa en la incidencia anual de diarrea (cuatro episodios vs. cinco) de infecciones respiratorias agudas bajas y de días con enfermedad severa; no debería reemplazar a las medidas de higiene ambiental (cloacas, agua potable, ventilación de ambientes, etc.) de educación (manejo de los utensilios, lavado de manos, cocción de los alimentos, etc.) de nutrición y de vacunación, de probada efectividad.

Ver glosario*

Mercedes Mutchinick [ Servicio de Medicina Familiar y Comunitaria del Hospital Italiano de Buenos Aires. mercedes.mutchinick@hospitalitaliano.org.ar ] Juan Pablo Mouesca [Pediatra, Monte Grande. juanpablomouesca@gmail.com ]

Mouesca J, Mutchinik M. El consumo de leche fortificada puede reducir la incidencia de diarrea y neumonía en la infancia. Evid Act Pract Ambul. 11(2) 38. Mar-Abr 2008. Comentado de: Sazawal S y col. Effects of fortified milk on morbidity in young children in north India: community based, randomised, double masked placebo controlled trial. BMJ. 2007 Jan 20; 334(7585):140. Epub 2006 Nov 28. PMID: 17132678. Disponible en URL: http://www.bmj.com/cgi/content/full/334/7585/140 (útimo acceso 20/03/08).

Referencia

1. O’Donnell A, Grippo B. Nutrición y desarrollo infantil. En: Desarrollo del niño en contexto. Editor: Horacio Lejarraga. Paidós. 2004. Pg:217-244.

2. Rainieri F. Alimentación complementaria oportuna en niños no amamantados. En: Programa Nacional de Actualización Pediátrica. Sociedad Argentina de Pediatría. 2007, Módulo 2 Pg 103-149.

3. Ministerio de Salud y Ambiente de la Nación. Encuesta Nacional de Nutrición y Salud. 2005. Disponible en URL: http://www.msal.gov.ar/htm/Site/ennys/site/areastematicas.asp (último acceso 20/03/08). 